Dissertation

\title{
Essays in Comparative International Entrepreneurship Research
}

\author{
Johannes Kleinhempel ${ }^{1}$ \\ 1 The University of Manchester, Alliance Manchester Business School, Comparative \& International Business Group \\ Keywords: entrepreneurship, social capital, national culture, comparative international entrepreneurship research \\ https://doi.org/10.46697/001c.30075
}

\section{AIB Insights}

Vol. 21, Issue 4, 2021

\begin{abstract}
Entrepreneurship does not take place in a vacuum but is deeply embedded in its context. This dissertation proposes three new perspectives which highlight (1) the changing impact of socio-cultural conditions over the course of the venture creation process, (2) the persistence, portability, and intergenerational transmission of entrepreneurial culture, and (3) the different theoretical channels through which culture influences entrepreneurship. This dissertation advances three fresh perspectives which shed new light on the critical role of socio-cultural influences in comparative international entrepreneurship research.
\end{abstract}

\section{BIG QUESTION}

Given that entrepreneurs are rare and economically valuable, which socio-cultural contexts are more efficient at 'producing' and 'enabling' entrepreneurs and what are the mechanisms through which socio-cultural factors influence entrepreneurship?

\section{INTRODUCTION}

Entrepreneurship does not take place in a vacuum but is deeply embedded in its context. While one-in-two U.S. Americans would prefer to be self-employed, this number is one-in-three in the United Kingdom, one-in-four in Japan, and one-in-five in Sweden (European Commission, 2013a). Preferences for entrepreneurship differ substantially across countries. There are also sizable and persistent differences in entrepreneurial activity across countries (see Figure 1). Given that entrepreneurship is an important driver of innovation, job creation, wellbeing, and growth, these differences may have far-reaching consequences for individuals and economies alike. Understanding the drivers of the pronounced and persistent differences in entrepreneurship is of critical importance not just from an academic but also from a policy-making point of view.

A rich and rapidly growing literature in comparative international entrepreneurship research has flourished, particularly in the last two decades, driven by notable theoretical advances, the growing availability of internationally harmonized databases, and policy makers' and practitioners' interest in promoting entrepreneurship. This body of scholarship has attributed the international variation in en- trepreneurial activity partially to differences in (a) economic, (b) formal institutional, and (c) socio-cultural conditions. In my dissertation, I specifically focus on the role of socio-cultural conditions. First, socio-cultural conditions are relatively stable over time which makes these promising candidates for explaining the persistent differences in entrepreneurship. Second, such persistent differences in entrepreneurship have not only been observed across countries but also within countries, across regions (Figure 2) and among immigrants from different countries of origin (see Figure 3). This renders it unlikely that economic and formal institutional conditions can fully explain the persistent differences in entrepreneurial activity across different levels of analysis. Socio-cultural factors are promising candidates in explaining the pronounced and persistent differences in entrepreneurship.

Despite manifold analyses, however, our knowledge of the mechanisms through which socio-cultural factors influence entrepreneurial activity remains fragmented, the literature is characterized by mixed and partially conflicting findings, and the relation between socio-cultural conditions and has remained elusive (e.g. Hayton \& Cacciotti, 2013). For example, research has associated Hofstede's cultural dimension of uncertainty avoidance with entrepreneurship positively, nil, and negatively. These mixed findings make it difficult to state if and how socio-cultural conditions influence entrepreneurship.

My dissertation makes the case that these mixed findings may be driven by (a) the pooling of distinct theoretical mechanisms through which socio-cultural conditions influence entrepreneurship and (b) the difficulty of isolating socio-cultural effects from other contextual conditions. To address these critical conceptual challenges, three novel 

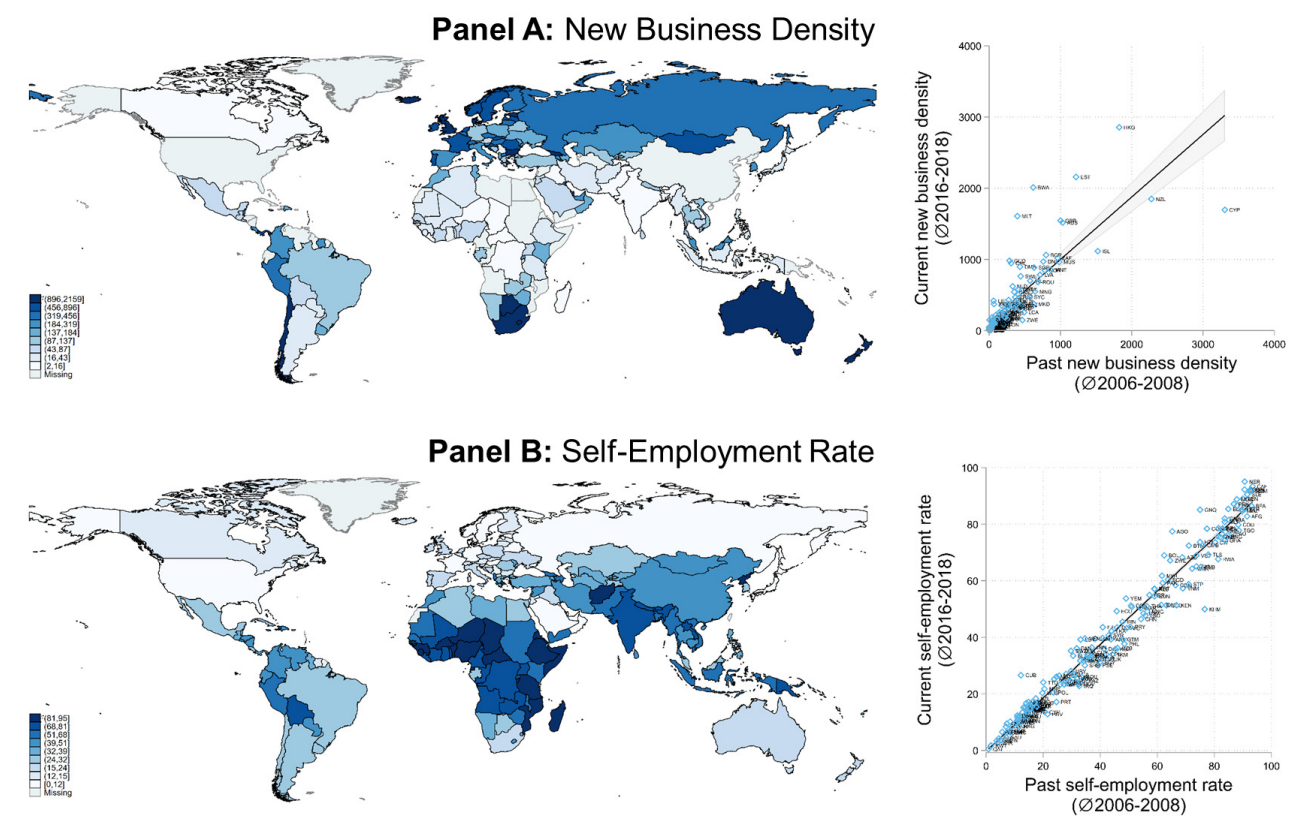

Panel B: Self-Employment Rate

Note: Two measures are plotted in the figure. New business density captures the number of new registrations per 1,000 people ages $15-64$. The self-employment rate is calculated as a percentage of total employment. These two measures complement one another and capture different facets of entrepreneurship. On the right-hand side, the contemporaneous values of new business density and self-employment rate (Ø2016-2018), respectively, are plotted on the world map. On the left-hand side, contemporaneous levels of new business
density and self-employment rate (Ø2016-2018), respectively, are plotted against their pastlevels ( $(2006-2008)$ Data stem from the World Bank World Development Indicators

Figure 1. Pronounced cross-country differences in entrepreneurship

perspectives on how socio-cultural conditions shape entrepreneurship are developed in this empirical three-essay dissertation. ${ }^{1}$ The overarching umbrella of this dissertation are these proposed perspectives as lenses that structure theorizing and testing to advance our understanding of the role of socio-cultural conditions in entrepreneurship.

\section{ESSAY 1-THE CHANGING ROLE OF SOCIAL CAPITAL DURING THE VENTURE CREATION PROCESS: A MULTILEVEL STUDY}

Many people would like to become entrepreneurs, yet few try, and even fewer manage to start a business or become self-employed. For example, while $50 \%$ of Londoners, $39 \%$ of Viennese, and 27\% of Stockholmers would rather be selfemployed than waged-employed, only $16 \%$ of Londoners, $11 \%$ of Viennese, and $11 \%$ of Stockholmers are actually selfemployed (European Commission, 2013a; Eurostat, 2019). This suggests that it may be fruitful to conceptualize entrepreneurship as a multi-staged process. Specifically, the comparison of Vienna and Stockholm suggests that preferences for entrepreneurship are higher in Vienna than in Stockholm, but that these preferences do not translate into action to the same degree. Incorporating this intermediate step-assessing preferences for entrepreneurship-changes the perspective: looking only at the self-employment rate may lead to the conclusion that Vienna and Stockholm are very similar even if transition rates from entrepreneurial preferences to actual entrepreneurial action are rather different. Treating entrepreneurship as a multi-staged process matters because it may expose when bottlenecks arise in the venture creation process.

Using societal social capital theory (Putnam, 1993) as the overarching theoretical framework, I bridge and synthesize the separate streams of (1) entrepreneurial process research and (2) comparative international entrepreneurship research. Based on the societal-level mechanisms of social capital theory and the individual-level mechanisms of process theory, I theorize-and assess empirically-whether the effect of regional social capital is contingent upon the situational characteristics faced by entrepreneurs in different stages of the venture creation process. Specifically, I argue that the positive effect of societal social capital-a resource that originates from voluntary associational networks-should be largest when individuals who want to become entrepreneurs attempt to mobilize the resources required to launch a venture formally. To test the hypotheses, I use a sequential logit logic in a multilevel setting and I relate regional social capital indicators for 110 regions to information on levels of entrepreneurial engagement for more than 22,000 individuals. The results indicate that regional social capital influences the new venture creation process positively, but at different stages to different de-

1 This is a summary of Kleinhempel (2020). Versions of Essay 1 and Essay 2 have been published as co-authored articles (Kleinhempel, Beugelsdijk, \& Klasing, 2020) or are currently undergoing review (Kleinhempel, Klasing, \& Beugelsdijk, 2021). Essay 3 is single-authored (Kleinhempel, 2021). 


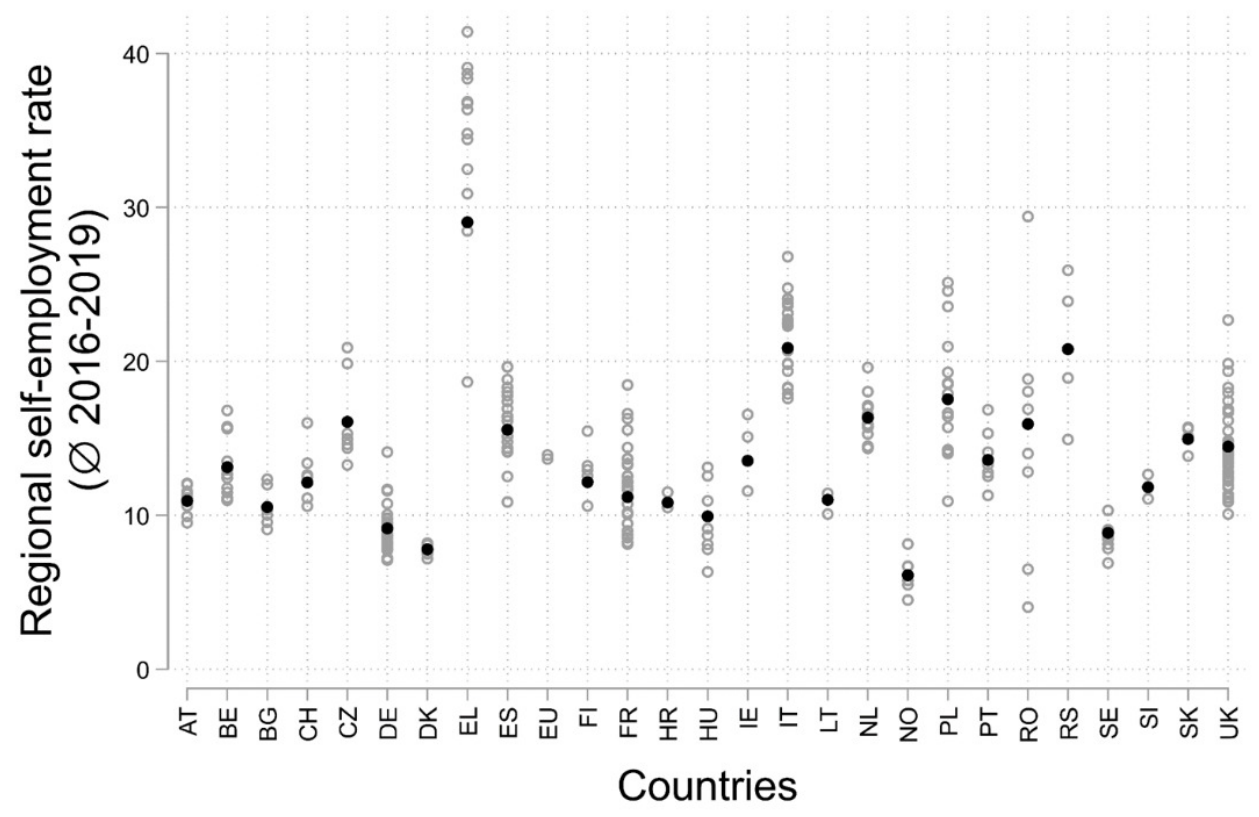

Note: Shown are the regional (grey) and national (black) self-employment rates for selected European countries. Data stem from Eurostat and are averaged over the period 2016-2019.

Figure 2. Within- and across-country variation in current self-employment rates in Europe

grees. Regional social capital is most relevant for the odds that individuals who want to start a business manage to do so, but regional social capital does not affect the likelihood that individuals become interested in entrepreneurship or that young ventures, once started, survive.

Combining the dynamic process perspective and the comparative perspective, this essay advances our understanding of entrepreneurship as a dynamic process in which the social context exerts a profound and changing influence. This novel dynamic perspective calls into question an (implicit) key assumption in comparative research: the assumption of a uniform impact of contextual factors on the different stages of the venture creation process. The findings highlight the need to relax this assumption of uniformity by instead assuming variability of contextual effects. This directly speaks to International Business scholarship that is concerned with the comparative analysis of contextual effects and it directly speaks to practitioners concerned with the analysis of entrepreneurship promotion programs.

\section{ESSAY 2-CULTURAL ROOTS OF ENTREPRENEURSHIP: EVIDENCE FROM SECOND-GENERATION IMMIGRANTS}

Does national culture influence entrepreneurship? A longstanding stream of scholarship has argued that some cultural orientations-for example, individualism and need for achievement-are conducive to entrepreneurship. To date, however, existing empirical evidence is partially conflicting and evidence for a causal effect of culture is lacking. Credibly relating culture to entrepreneurship requires isolating cultural effects from other contextual influences. This is difficult because the central macro-level determinants of entrepreneurship-economic, formal institutional, and socio-cultural conditions-are inherently interdependent. Figure 4 visualizes these interdependencies: we clearly see that the four factors are related to one another. Consequently, it is very difficult to attribute the international variation in entrepreneurship to cross-national variation in culture.

To confront this challenge, I study the likelihood that second-generation immigrants of different ancestries are self-employed. Second-generation immigrants have been born and live in one country-and thus operate in a shared economic and institutional context-but were raised by parents who stem from different countries. Given that national culture is durable, portable, and intergenerationally transmitted, I hypothesize that individuals are more likely to become entrepreneurs if their parents stem from countries with a strong entrepreneurial culture. Empirically, I build and analyze a database that covers more than $55,000 \mathrm{sec}-$ ond-generation immigrants who were born in the U.S. but stem from 40 different countries of ancestry. Using multilevel modelling, I relate differences in country-of-ancestry entrepreneurial culture to the odds that second-generation immigrants are entrepreneurs. The results demonstrate that second-generation immigrants are more likely to be entrepreneurs if their parents stem from countries with a strong entrepreneurial culture. I cross-validate the analysis using a second dataset of second-generation immigrants who were born in Europe that corroborates the positive link between country-of-ancestry entrepreneurial culture and second-generation immigrants' odds of self-employment. I also show that these results are robust to accounting for alternative non-cultural explanations such as differences in resource holdings, entrepreneurship-specific human capital, and discrimination. Taken together, these 


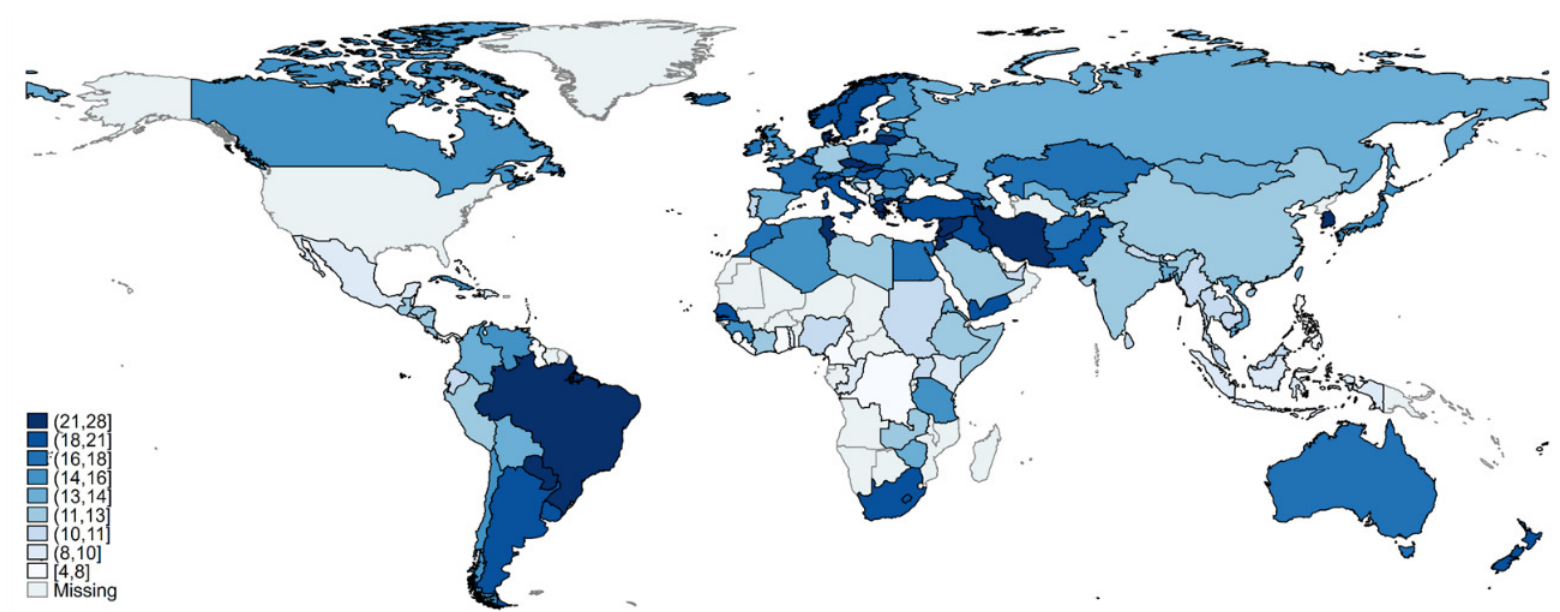

Note: Plotted are the average self-employment rates of immigrants in the U.S. by country of origin. Data stem from U.S. Decennial Census and American Community Survey files obtained from IPUMS USA (2000-2019). The sample used in calculating the averages are first-generation immigrants aged between 18 and 65 who have lived in the U.S. for at least 10 years. Only individuals who are active in the labor force and work in non-agricultural industries are considered. Excluded are immigrants who only indicated their broad geographical origin (e.g. European or Africa). I impose a threshold of at least 100 observations per country of origin and exclude countries of origin which cannot be matched to currently existing countries.

Figure 3. Immigrant self-employment rates by country of origin - immigrants in the U.S.

findings suggest that culture is durable, portable, intergenerationally-transmitted, and that culture influences entrepreneurship in a likely causal way.

\section{ESSAY 3-HOW DOES CULTURE INFLUENCE ENTREPRENEURSHIP? EVIDENCE FROM THE AGGREGATE TRAITS PERSPECTIVE}

How does national culture influence entrepreneurship? There are three distinct theoretical perspectives on how variations in national culture influence entrepreneurial activity: culture influences entrepreneurship by shaping individuals' values and traits, through the normative legitimacy of entrepreneurship, and through norms related to social support. These perspectives differ conceptually and lead to partially opposing predictions. However, because it is difficult to disentangle these perspectives conceptually and empirically, progress on identifying the mechanisms through which culture influences entrepreneurship has stalled. While few social scientists would disagree with the thesis that culture matters-for entrepreneurship and beyond-we know relatively little about how it matters.

Against this backdrop, I argue that one way of advancing the culture and entrepreneurship literature is to focus on the identification of the underlying theoretical mechanisms through which culture influences entrepreneurship. To undertake a first step in that direction, I focus on the isolation of cultural effects from the aggregate traits perspective. Following Essay 2 and studying second-generation immigrants of different ancestries, I zoom in on intergenerationally transmitted internalized cultural dispositions while holding societal level normative influences relatively constant. Specifically, I hypothesize that cultural risk-taking propensity, cultural need for achievement, and cultural need for autonomy are positively related to entrepreneurship.

Testing these hypotheses using multilevel modelling and a sample of more than 53,000 second-generation immigrants of 36 ancestries in the U.S., cultural need for autonomy emerges as the quantitatively most important and robust predictor. Post-hoc, I also show that cultural need for autonomy drives the effect of general entrepreneurial culture on self-employment which was derived in Essay 2. Furthermore, in a second post-hoc test, I use mediation analysis to document that culture influences entrepreneurship through its effect on individuals' values. This essay underscores the importance of disentangling the distinct theoretical perspectives on how culture influences entrepreneurship and it provides empirical evidence for the frequently assumed but rarely tested mechanism that culture influences entrepreneurship (partially) through individuals' dispositions.

\section{IMPLICATIONS AND CONCLUSION}

Why is entrepreneurial activity more common in some contexts than in others? This is a pressing question for policymakers around the globe seeking to encourage entrepreneurship, for managers wishing to promote intrapreneurship and corporate entrepreneurship, and for individuals who aspire to launch a firm who are assessing potential markets and locations.

Many organizations, governments, and international organizations have developed entrepreneurship promotion programs (e.g. European Commission, 2013b; OECD, 2020, 2021). These programs try to facilitate entrepreneurship by making structural adjustments, e.g. improving the economic and formal institutional conditions, and by equipping individuals with the skills, networks, resources, and self-efficacy to launch ventures. However, these programs have generally placed less emphasis on improving the socio-cultural conditions.

My findings offer potentially important implications for practitioners and policy-makers by highlighting that entre- 


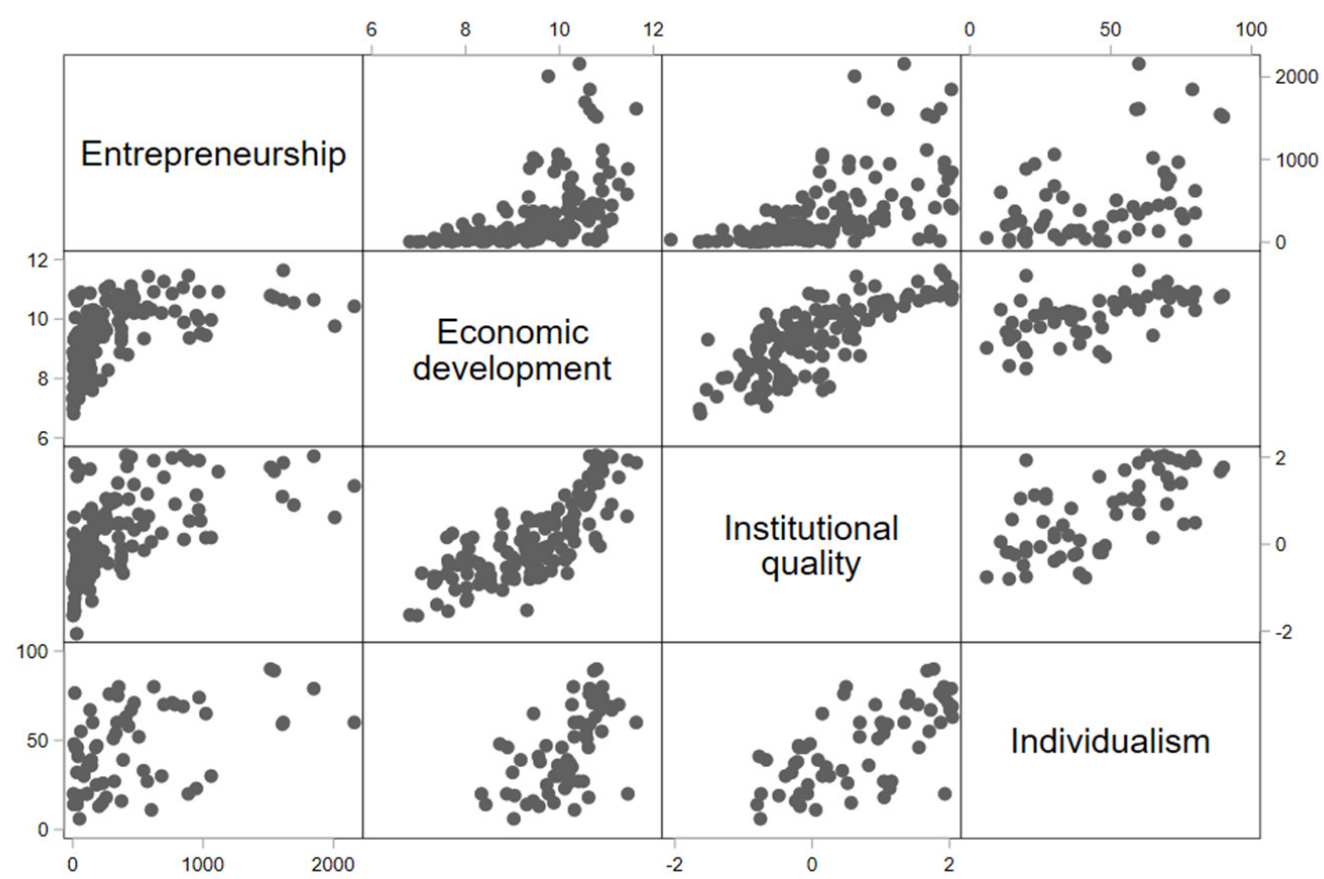

Note: Shown are the scatterplots between entrepreneurship-operationalized as new business density-, economic development, institutional quality, and individualism. For example, the first scatterplot in the first row visualizes the relation between entrepreneurship (y-axis) and economic development (x-axis). Data stem from the World Development Indicators (Ø2016-2018) and Geert Hofstede. New business density captures the number of new firm registrations per 1,000 people ages 15-64. Economic development is operationalized as In GDP per capita. Institutional quality is the first principal component of the six World Governance Indicators. Individualism refers to Hofstede's measure.

Figure 4. Scatterplots highlighting the interdependence of entrepreneurship and its contextual drivers

preneurial undertakings are embedded in their socio-cultural context. First, regional social capital which originates from voluntary associations generates positive spillover effects of a public goods nature that facilitate entrepreneurship and innovation. Since regional social capital is substantially more malleable than for example cultural values or norms, it may be strengthened by enhancing the conditions for membership and participation in voluntary associations. For example, the provision of physical meeting spaces, shared by multiple associations, could enhance membership in voluntary associations, foster the creation of weak and cross-cutting ties, and facilitate the emergence of regional social capital. Vice versa, policy changes that influence membership in voluntary associations negatively either directly or indirectly-such as reducing the financial support for associations-may be associated with unintendedly large negative externalities. Short-term public savings could be more than offset by the losses of positive spillovers generated from membership in voluntary associations.

Second, intergenerationally-transmitted cultural dispositions shape individuals' propensity for entrepreneurship even if individuals face the same markets and the same institutions. Cultural imprints are durable and consequential. While it may be hard to change intergenerationally-transmitted values and dispositions in the short- and mediumrun, the prevailing socio-cultural conditions should be considered when developing entrepreneurship education and promotion programs. While the role of socio-cultural conditions is generally acknowledged (European Commission, 2013b; Isenberg, 2011), more efforts are needed to develop an understanding of which interventions are particularly fruitful under which socio-cultural conditions and to launch context-sensitive programs. It is time to "revolutionize the culture of entrepreneurship in Europe" (European Commission, 2013b).

My research provides fresh insights into how socio-cultural conditions shape entrepreneurship. First, adopting an explicit process lens when theorizing on social-cultural effects and moving from static towards dynamic perspectives advances our understanding of how, when, and why sociocultural contextual effects matter. Second, the durability, portability, and intergenerational transmission of culture are central imprinting mechanisms that enable the isolation of cultural effects in entrepreneurship and beyond. Culture influences entrepreneurship in a likely causal way. Third, disentangling the distinct perspectives through which culture influences entrepreneurship is crucial for gauging the underlying mechanisms. This thesis adds fresh perspectives to comparative international entrepreneurship research which underline the critical importance of sociocultural effects in entrepreneurship.

\section{ACKNOWLEDGMENTS}

I am grateful to Sjoerd Beugelsdijk and Mariko Klasing for invaluable guidance. I also would like to express my grat- 
itude to Saul Estrin, Ute Stephan, and Harry Garretsen, as well as to Juliette de Wit and Tobias Grohmann.

\section{ABOUT THE AUTHOR}

Johannes Kleinhempel (johannes.kleinhempel@manchester.ac.uk) is a Presidential Academic Fellow of Comparative and International Business at Alliance Manchester Business School, The University of Manchester. He received his Ph.D. (cum laude) in Economics and Business from the University of Groningen. The dissertation has received the European
International Business Academy (EIBA) Best Doctoral Thesis Proposal Award and it has been nominated for the Academy of International Business (AIB) Buckley and Casson Dissertation Award, the Academy of Management (AOM) NFIB Dissertation Award, and the 2018-2021 SSE Gunnar Hedlund Dissertation Award. Johannes' main research interests are in comparative international business and entrepreneurship research.

Submitted: September 24, 2021 EST, Accepted: November 24, 2021 EST 


\section{REFERENCES}

European Commission. 2013a. Flash Eurobarometer 354 (Entrepreneurship in the EU and Beyond). GESIS Data Archive, Cologne. ZA5789 data file Version 1.0.0. https://doi.org/10.4232/1.11590.

European Commission. 2013b. Entrepreneurship 2020 Action Plan: Reigniting the entrepreneurial spirit in Europe. European Commision - DG Enterprise \& Industry. Brussels, Belgium.

Eurostat. 2019, May 22. Eurostat Regions Database. European Commission. https://ec.europa.eu/eurostat/ data/database.

Hayton, J. C., \& Cacciotti, G. 2013. Is there an entrepreneurial culture? A review of empirical research. Entrepreneurship \& Regional Development, 25(9-10): 708-731.

Isenberg, D. J. 2011. The Entrepreneurship Ecosystem Strategy as a New Paradigm for Economic Policy: Principles for Cultivating Entrepreneurship. Babson College, Babson Park: MA.

Kleinhempel, J. 2020. Essays in Comparative International Entrepreneurship Research. Ph.D. Thesis: University of Groningen, Groningen, The Netherlands. Ipskamp Printing, Enschede, The Netherlands, ISBN 9789403422800.
Kleinhempel, J. 2021. How does culture influence entrepreneurship? Evidence from the aggregate traits perspective. Working paper.

Kleinhempel, J., Beugelsdijk, S., \& Klasing, M. J. 2020. The Changing Role of Social Capital During the Venture Creation Process: A Multilevel Study. Entrepreneurship Theory and Practice. Forthcoming.

Kleinhempel, J., Klasing, M. J., \& Beugelsdijk, S. 2021. Cultural Roots of Entrepreneurship: Evidence from Second-Generation Immigrants. Working paper.

OECD. 2020. International Compendium of Entrepreneurship Policies. OECD Studies on SMEs and Entrepreneurship, OECD Publishing, Paris: OECD. https://doi.org/10.1787/338f1873-en.

OECD. 2021. Inclusive Entrepreneurship Policies: Country Assessment Notes. OECD Publishing, Paris. https://www.oecd.org/cfe/smes/Inclusive-Entreprene urship-Policies-Country-Assessment-Notes.htm.

Putnam, R. D. 1993. Making Democracy Work: Civic Traditions in Modern Italy. Princeton, NJ: Princeton University Press. 